\title{
ANALYSIS ON TEMPORAL-SPATIAL CHANGES OF VEGETATION CVERRGE IN FARMING-PASTORAL ECOTONE OF INNER MONGOLIA
}

\author{
Xiaoxiao YAN ${ }^{1}$, Jing $\mathrm{LI}^{1}$, Zhen YANG ${ }^{1}$ \\ 1. College of Geoscience and Surveying Engineering, China University of Mining and Technology (Beijing), Beijing 100083, China
}

CommissionIII, WG III/10

\begin{abstract}
KEY WORDS: Chen Barag Banner, Farming-pastoral ecotone, Vegetation coverage, Pixel decomposition model, Temporal-spatial analysis
\end{abstract}

\begin{abstract}
:
Chen Barag Banner is located in the typical farming-pastoral ecotone of Inner Mongolia, and it is also the core area of Hulunbuir steppe. Typical agricultural and pastoral staggered production mode so that the vegetation growth of the region not only determines the local ecological environment, and animal husbandry production, but also have a significant impact on the whole Hulunbuir ecological security and economic development. Therefore, it is necessary to monitor the change of vegetation in this area. Based on 17 MODIS Normalized Difference Vegetation Index (NDVI) images, the authors reconstructed the dynamic change characteristics of Fraction vegetation coverage (FVC) in Chen Barag Banner from 2000 to 2016. In this paper, first at all, Pixel Decomposition Models was introduced to inversion FVC, and the time series of vegetation coverage was reconstructed. Then we analyzed the temporal-spatial changes of FVC by employing transition matrix. Finally, through image analyzing and processing, the results showed that the vegetation coverage in the study area was influenced by effectors including climate, topography and human actives. In the past 17 years, the overall effect of vegetation coverage showed a downward trend of fluctuation. The average vegetation coverage decreased from $58.81 \%$ in 2000 to $48.14 \%$ in 2016 , and the area of vegetation cover degradation accounts for $40.09 \%$ of the total change area. Therefore, the overall degradation trend was obvious.
\end{abstract}

\section{INTRODUCTION}

Hulunbuir Steppe in the Inner Mongolia, belongs to the northern frontier of China where is an important green ecological security barrier in the north of China, its territory is one of the three natural grasslands in the world, and also a typical ecological fragile area in China (Liu et al., 2008). Chen Barag Banner is located in Hulunbuir grassland hinterland, grassland core area "animal husbandry four flags" one of the unique. So the dynamic changes of vegetation coverage in Hulunbuir Steppe have become a public focus among recent researches (e.g. Li et al., 2010; Zhu et al., 2011). Peng et al., 2016 conducted a survey on temporal-spatial changes of Vegetation Coverage in Hulunbuir Steppe during 2001-2010. Chen (2008) pointed out that the ecological environment of Chen Barag Banner tends to deteriorate. And other authors also made a study on responses of vegetation changes to climatic factors and human activities in Hulunbuir Steppe, they arguing that vegetation degradation had strong correlation with the factors such as transition grazing, urban construction, disorderly excavation, open pit coal mine development and climate change (Feng et al., 2013). However, most of the researches are qualitative analysis or dual-phase analysis of land type transformation (Liu et al., 2017). And, the change process of ecological significance is conceptualized by transition, which cannot reveal the spatial characteristics and change process track of long time sequence area. In this paper, we conducted qualitative and quantitative analysis of the changing trend of the vegetation for the study area using inter-annual MODIS NDVI time series data. It is our objective to provide reference for grassland ecological protection and evaluate the cumulative effect quantitative for the study area.

\section{STUDY AREA AND DATA}

\subsection{Study area}

Chen Barag Banner, with the location of longitude $118^{\circ} 22^{\prime}-121^{\circ}$ $02^{\prime}$ and latitude $48^{\circ} 48^{\prime}-50^{\circ} 12^{\prime}$, located in the northwest part of Hulunbuir of Inner Mongolia. The eastern part of the study area is a temperate sub-humid continental climate with a temperate, semi-arid continental climate in other regions. With the difference of climate, the main types of vegetation are the forest and the desert steppe. In this study, the study area (Figure 1) is made up of 8 Banners of which Baorixile town is a coal mining town since 1985 , the total coal reserves of 10.5 billion tons.

\subsection{Data}

The MOD13Q1 data, with global coverage at 250-m spatial resolution, accessible to download from (https: // modis. gsfc. nasa. gov/ ), ranging from 2000 to 2016, is used in this study. The tiles of image over the study area are consisted of h $25 \mathrm{v} 03$, $\mathrm{h} 25 \mathrm{v} 04$, and in which at a 16-day time resolution. Moreover, administrative data based on the vectorization of the 2007 Inner Mongolia Township, was obtained from the international scientific data sharing platform of the computer network information center, which the Chinese Academy of Sciences. The land use, land-cover data come from GLC30 information service website (http://www.globallandcover.com/GLC30Download/index.aspx ). It is the global $30 \mathrm{~m}$ surface covering product developed by the National Geographic Information Center in 2000 and 2010 in the two basic years (Figure 2). 


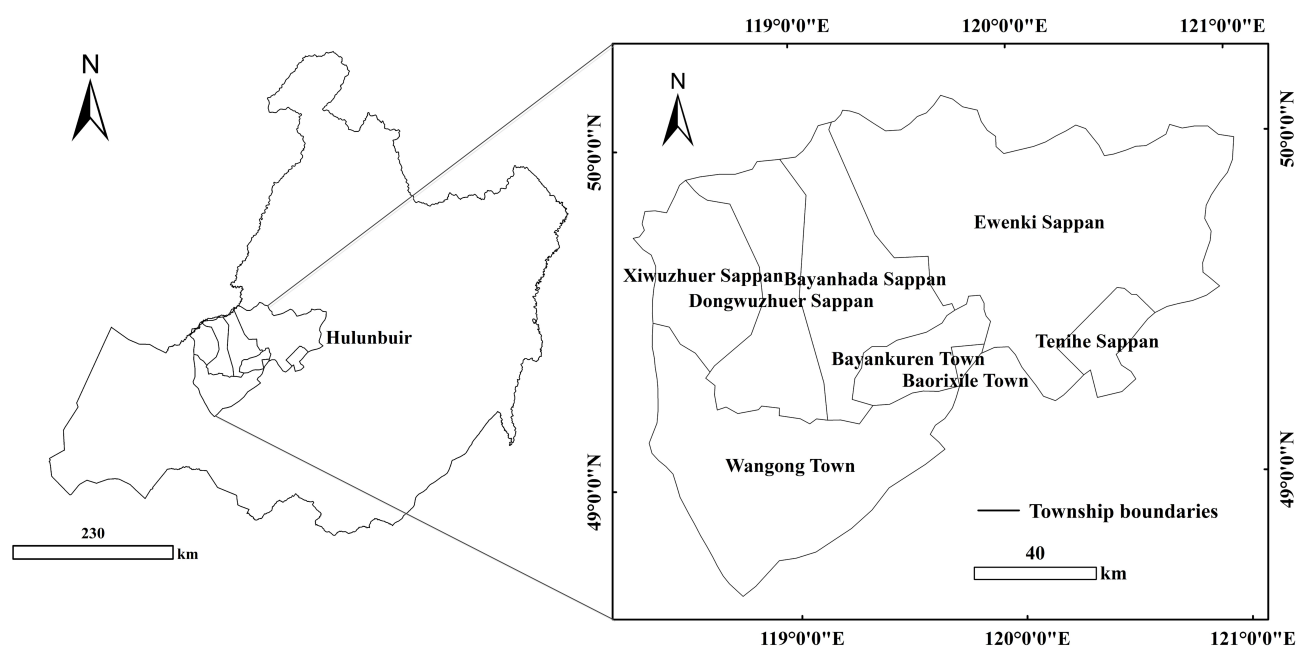

Figure 1. Location map of the study area
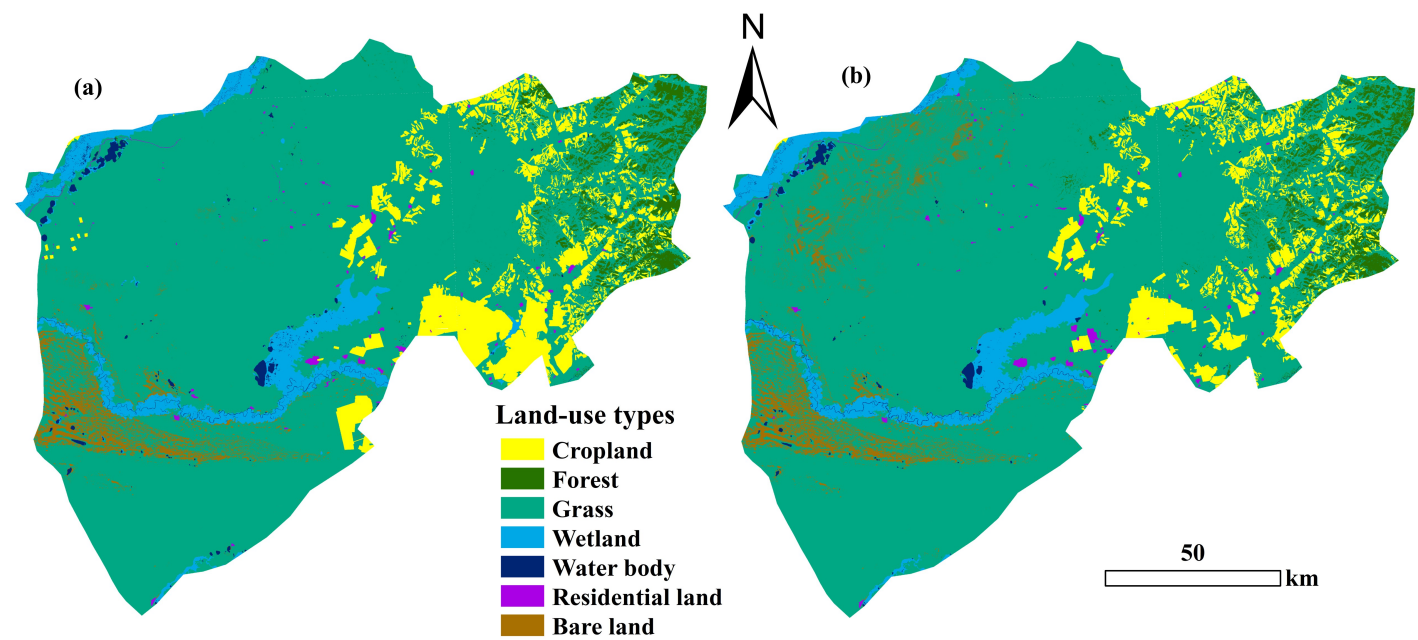

Figure 2. Land use, land-cover data (Figure a refers to 2000, Figure b refers to 2010)

\section{METHODS}

\subsection{The estimation model of FVC}

Inversion of vegetation coverage by pixel decomposition model, which was introduced by Chen et al., 2001. The Eq. (1) as follows:

$$
F V C=\frac{N D V I-N D V I_{\text {soil }}}{N D V I_{\text {veg }}-N D V I_{\text {soil }}}
$$

Where, $\mathrm{NDVI}_{\text {soil }}$ and $\mathrm{NDVI}_{\text {veg }}$ is the gray-value of pixel absolutely covered by soil and vegetation, respectively. But, it is not advisable to adopt a determined value of $N D V I_{\text {veg }}$ and $N D V I_{\text {soil }}$ in fact. And the two referring values were set based on a cumulative frequency for 0.5 and 99.5 to NDVI in fact, respectively (Table 1).

\begin{tabular}{|c|c|c|}
\hline Year & NDVI $_{\text {veg }}$ & NDVI $_{\text {soil }}$ \\
\hline 2000 & 0.905 & 0.244 \\
\hline 2001 & 0.896 & 0.249 \\
\hline 2002 & 0.901 & 0.32 \\
\hline 2003 & 0.899 & 0.306 \\
\hline 2004 & 0.906 & 0.256 \\
\hline 2005 & 0.91 & 0.319 \\
\hline 2006 & 0.897 & 0.284 \\
\hline
\end{tabular}

\begin{tabular}{|c|c|c|}
\hline 2007 & 0.889 & 0.247 \\
\hline 2008 & 0.91 & 0.36 \\
\hline 2009 & 0.901 & 0.309 \\
\hline 2010 & 0.92 & 0.331 \\
\hline 2011 & 0.905 & 0.33 \\
\hline 2012 & 0.895 & 0.312 \\
\hline 2013 & 0.916 & 0.326 \\
\hline 2014 & 0.918 & 0.336 \\
\hline 2015 & 0.897 & 0.305 \\
\hline 2016 & 0.903 & 0.225 \\
\hline
\end{tabular}

Table 1. Corresponding NDVI value for $\mathrm{NDVI}_{\mathrm{veg}}$ and $\mathrm{NDVI}_{\text {soil }}$ during from 2000-2016 in Chen Barag Banner

\subsection{Analysis of temporal-spatial variation characteristics}

Based on the calculation results of FVC and land use data, we select the characteristic pixels of grassland categories and extract the time series of FVC using the Eq. (3) as follows:

$$
\overline{F V C_{i}}=\frac{\sum_{j=1}^{n} f_{\mathrm{c} i j}}{n}
$$

Where, $\overline{F V C_{\mathrm{i}}}$ is the mean of $i$ years of vegetation coverage in the study area, $i=1,2, \ldots, 17$ is the annual sequence number; $f_{\mathrm{cij}}$ 
is the vegetation coverage value of $\mathrm{j}$ pixels in $i$ years in the region, and $n$ is the total pixel number in the study area.

In order to further study the temporal variation of vegetation coverage in grassland, the change of vegetation coverage in 2000 and 2016 was analyzed by transfer matrix method (Peng et al., 2016). This research has made the corresponding adjustment to the vegetation coverage based on hierarchical classification arithmetic. That is: $\mathrm{FVC}<20 \%$ is a lowest coverage area; $20 \%<$ $\mathrm{FVC}<40 \%$ is a low coverage area, $40 \%<\mathrm{FVC}<65 \%$ is a mediate coverage area; $65 \%<\mathrm{FVC}$ is a high vegetation coverage area.

The following formula (4) is used to calculate the proportion of the vegetation coverage of the pixel, from one period to another (Tian et al., 2014).

$$
P=\sum_{i=1}^{n} p_{i i}
$$

Where, $P$ represents the proportion of vegetation coverage type unchanged from one period to another. $\mathrm{P}_{i i}$ is the number of $i$ lines, $i$ columns in the transfer matrix, that is, the $i$ values on the main diagonal line. And, $n$ is the number of coverage classes.

\section{RESULTS}

\subsection{Change of land use structure}

According to the results of classification of land use in 2000 and 2010 (Table 2), it is noted that in the past 10 years the area of bare land and residential land was increased $46.35 \%$ and $21.84 \%$, respectively, which was more significant. In addition, the area of cropland and water body is reduced by $23.48 \%$ and $17.89 \%$, respectively. And, the area of forest reduced by $5.08 \%$. The changes in other land classes are relatively insignificant.

\begin{tabular}{|c|c|c|c|c|c|c|c|c|}
\hline \multicolumn{2}{|c|}{ Project } & Forest & Grass & Wetland & $\begin{array}{c}\text { Water } \\
\text { body }\end{array}$ & Cropland & $\begin{array}{c}\text { Residential } \\
\text { land }\end{array}$ & Bare land \\
\hline \multirow{2}{*}{ Area/ $/ \mathrm{km}^{2}$} & 2000 & 575.52 & 14381.92 & 967.97 & 141.77 & 1653.27 & 69.39 & 463.39 \\
\cline { 2 - 10 } & 2010 & 546.30 & 14610.09 & 952.55 & 116.41 & 1265.16 & 84.55 & 678.18 \\
\hline \multirow{2}{*}{ Proportion/\% } & 2000 & 3.15 & 78.79 & 5.30 & 0.78 & 9.06 & 0.38 & 2.54 \\
\cline { 2 - 10 } & 2010 & 2.99 & 80.04 & 5.22 & 0.64 & 6.93 & 0.46 & 3.72 \\
\hline \multicolumn{2}{|c|}{ Change type/\% } & -5.08 & +1.59 & -1.59 & -17.89 & -23.48 & +21.84 & +46.35 \\
\hline
\end{tabular}

Table 2. Area of major land use type change from 2000 to 2010

\subsection{Spatial-temporal change of FVC}

The annual average FVC of the study area from 2000 to 2016 was extracted, and 17 years' FVC time series (a) and its trend extraction results (b) were obtained, as shown in Figure 3. According to the results, it shows that the linear variation trend of average FVC is not significant in the study area, and the overall FVC showed a slight downward trend and the interannual fluctuations are relatively large, with a certain periodicity. It has a certain periodicity and the total range is between 0.45 and 0.75 . FVC in the whole area reached its peak for the first time in 2002, which was 0.725 . From 2003 to 2016, there were 3 valley values in 2004, 2007 and 2016, which values were $0.562,0.539$ and 0.481 , respectively.

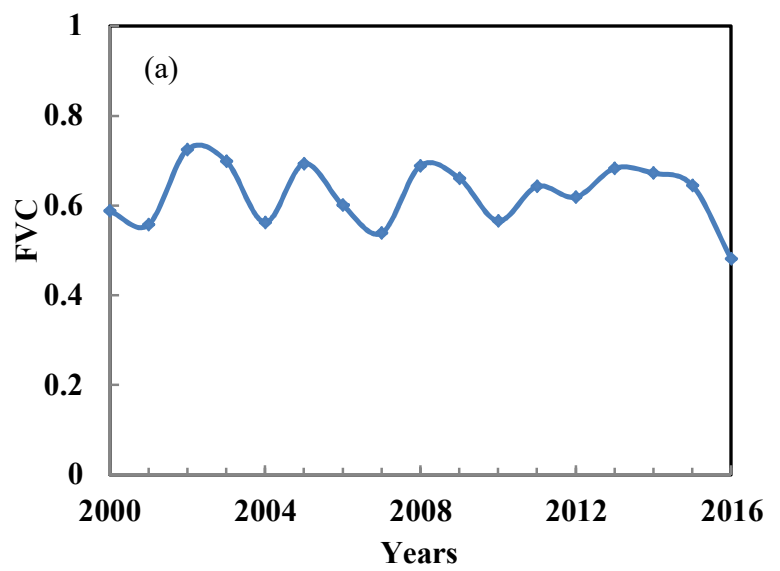

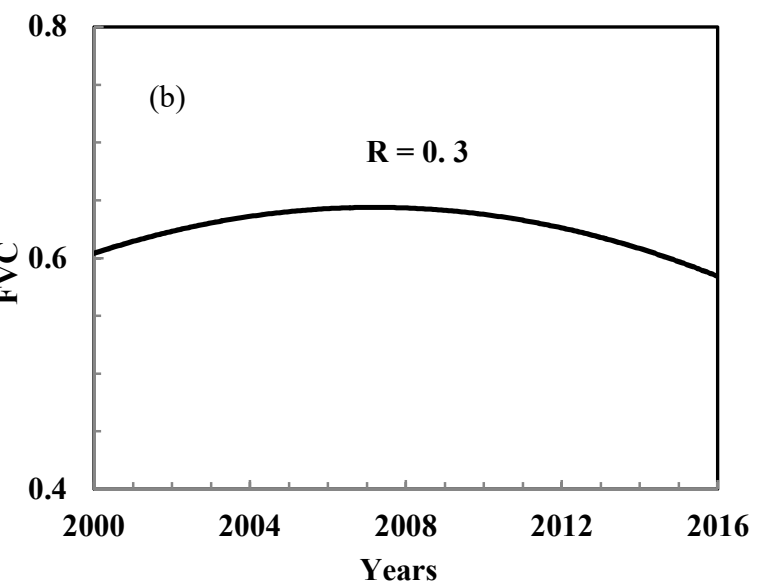

Figure 3. Time series (a) and its result of tendency term extracted (b) from average FVC over 17 years

Annual accumulated FVC anomaly (Figure 4) shows that the negative values of 2000,2001, 2006, 2007, 2010, 2012and 2016 are positive for the last 17 years. Except for 2016, the interannual fluctuation of NDV I is not significant $(-0.1 \sim 0.1)$. Furthermore, in 2001, 2004, 2007, 2010 and 2016, there were 5 points obvious lows in NDVI. The annual anomaly was about $-0.07,-0.06,-0.87,-0.059$ and -0.144 , respectively, indicating that the growth of vegetation in these 5 years is worse than that in other years. In general, negative anomaly is greater than positive anomaly. The vegetation growth in the region has gradually developed in the worst direction in the past 17 years. 


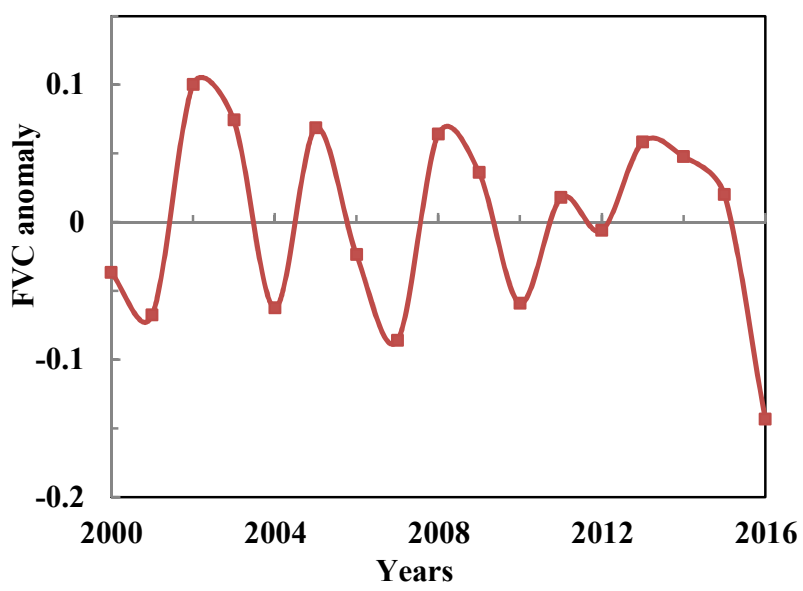

Figure 4. Times series of annual accumulated FVC anomaly of the study area

In the past 17 years, spatial distribution of vegetation coverage changes in Chen Barag Banner as shown in Figure-5. The results showed that in the past 17 years, the high vegetation covered areas were mainly distributed in the east forest-grass transition area, which is $24.27 \%$ of the total area. Moreover, the mediate vegetation covered areas were mainly distributed in the northern part of the research area, which is $8.66 \%$ of the total area. And the lowest vegetation covered areas were mainly distributed in sandy belt of the Wangong Town. Meanwhile, the changes area of vegetation cover accounts for $61.96 \%$ of the whole area and is widely distributed.

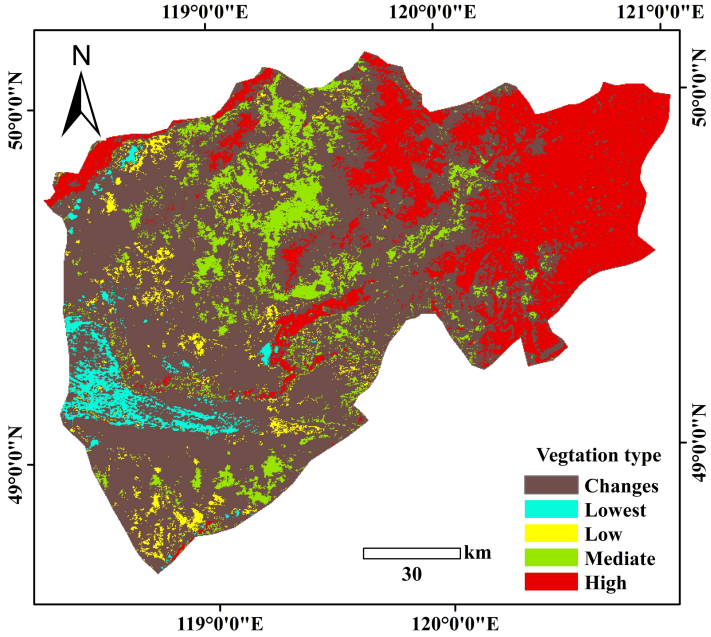

Figure 5. Temporal-spatial type evolution from 2000 to 2016

The change transfer matrix for vegetation coverage in 2000-2010 and 2010-2016 are shown in Table 3 and 4, respectively. Overall, 17 years the effect of vegetation coverage from high to lowest is the transformation trend, and the area of vegetation degradation is $40.09 \%$.

$\mathrm{P}=59.84 \%$ can be obtained from Table 3, which indicates that there is no change in the type of vegetation coverage in $59.84 \%$ of the region in the past 2000-2010 years. In the changing type, the proportion from the high vegetation coverage to the mediate coverage is higher than others type, $15.16 \%$. From Table 4 we can see that $\mathrm{P}=53.59 \%$ in the past $2010-2016$ years. In the changing type, the proportion from the mediate vegetation coverage to the low coverage is higher, $20.46 \%$. Moreover, the area of vegetation degradation is higher than that of the previous ten years.

\begin{tabular}{|c|c|c|c|c|c|c|}
\hline \multirow{2}{*}{\multicolumn{2}{|c|}{ Project }} & \multicolumn{5}{|c|}{2000} \\
\hline & & Lowest & Low & Mediate & High & Total \\
\hline \multirow{5}{*}{2010} & Lowest & $2.82 \%$ & $0.50 \%$ & $0.12 \%$ & $0.05 \%$ & $3.50 \%$ \\
\hline & Low & $3.88 \%$ & $5.79 \%$ & $3.94 \%$ & $0.64 \%$ & $14.26 \%$ \\
\hline & Mediate & $2.07 \%$ & $11.46 \%$ & $21.21 \%$ & $15.16 \%$ & $49.89 \%$ \\
\hline & High & $0.19 \%$ & $0.71 \%$ & $1.43 \%$ & $30.02 \%$ & $32.35 \%$ \\
\hline & Total & $8.97 \%$ & $18.45 \%$ & $26.71 \%$ & $45.87 \%$ & $100 \%$ \\
\hline
\end{tabular}

Table 3. The vegetation fractional cover change transition matrix from 2000 to 2010

\begin{tabular}{|c|c|c|c|c|c|c|}
\hline \multirow{2}{*}{\multicolumn{2}{|c|}{ Project }} & \multicolumn{5}{|c|}{2010} \\
\hline & & Lowest & Low & Mediate & High & Total \\
\hline \multirow{5}{*}{2016} & Lowest & $3.21 \%$ & $6.64 \%$ & $6.13 \%$ & $0.25 \%$ & $16.23 \%$ \\
\hline & Low & $0.21 \%$ & $5.78 \%$ & $20.46 \%$ & $1.03 \%$ & $27.48 \%$ \\
\hline & Mediate & $0.07 \%$ & $1.66 \%$ & $19.24 \%$ & $5.71 \%$ & $26.68 \%$ \\
\hline & High & $0.02 \%$ & $0.18 \%$ & $4.06 \%$ & $25.36 \%$ & $29.61 \%$ \\
\hline & Total & $3.50 \%$ & $14.26 \%$ & $49.89 \%$ & $32.35 \%$ & $100 \%$ \\
\hline
\end{tabular}

Table 4 . The vegetation fractional cover change transition matrix from 2010 to 2016

\section{CONCLUSIONS AND DISCUSSION}

In this paper, the temporal-spatial changes of FVC in study area were analyzed. The higher level vegetation coverage mainly distributed in the east of study area; the lower level of that mainly distributed in the west of study area. Especially, the lowest vegetation coverage in the south-western of the study area is the lowest. The vegetation coverage of whole study area was showed a slight downward trend and the interannual fluctuations are relatively large in the 17 years. Additionally, the changes area of vegetation cover accounts for $61.96 \%$ of the whole area, and the area of vegetation degradation is $40.09 \%$. The vegetation degradation trend more obvious. The degradation of grassland in the study area is what we must pay attention to. And there are also many uncertain influence factors, such as social-economic factors, need to be further studied. 


\section{REFERENCES}

Feng, Y., Wang, W.J., Liu, J.H., Wu, H., Ma, S. and Nie, X.Y., 2013.Spatial and temporal variation of main impact factors and importance of wind break and sand-fixing function in Hulun Buir Grassland Eco-function Area. Journal of Environmental Engineering Technology, 3(3), pp. 220-230.

Liu, D.X., Lu, X.S., 2008. Evaluation of eco-environmental vulnerability of grassland in Hulunbeier steppe. Journal of China Agricultural University, 13(5), pp. 48-54.

Liu, X.R., Hu, Z.Q., Xu, T. and Zhu, Q., 2017. Remoting sensing monitoring and analysis of Hulunbuir Grassland cover changes in the year 2000 to 2010. Journal of China Agricultural University, 22(5), pp. 118-127.

Peng, F., Fan, W.J., Xu, X.R. and Liu, X., 2017. Analysis on temporal-spatial change of vegetation coverage in Hulunbuir Steppe (2000-2014). Acta Scientiarum Naturalium Universitatis Pekinensis, 53(03), pp. 563-572.

Chen, Q.H., 2008. The ecological fragile area of grassland animal husbandry development: Based on the investigation of Hulun Buir City Chenbaerhuqi. Northern Economy, pp. 32-33.

Li, Y., Zhang, F., Wang, Q., 2010. Analysis of dynamic change of Hulunbeier Grassland vegetation coverage. Journal of Arid Land Resources and Environment, 27(6), pp. 126-131.

Mu, S.J., Li, J.L., Chen, Y.Z., Gang, C.C., Zhou, W. and JU, W.M., 2012. Spatial Differences of Variations of Vegetation Coverage in Inner Mongolia during 2001-2010. Journal of Geographical Science, 67(9), pp. 1255-1268.

Zhu, J.F., Xing, B.L., Ju, W.M., Zhu, G.L. and Liu, Y.B., 2011. Remote-sensing estimation of grassland vegetation coverage in Inner Mongolia, China. Chinese Journal of Plant Ecology, 35(6), pp. 615-622.

Tian, H.J., Cao, C.X., Dai, S.M., Zheng, S., Lu, S.L., Xu, M., Chen, W., Zhao, J., Liu, D. and Zhu, H.Y., 2014. Analysis of Vegetation Fractional Cover in Jungar Banner Based on Time-series Remote Sensing Data. Journal of Geo-Information science, 16(1), pp. 126-133. 